\title{
Exploring the impact of patient views on 'appropriate' use of services and help seeking: a mixed method study
}

\author{
Joy Adamson, Yoav Ben-Shlomo, Nish Chaturvedi and Jenny Donovan
}

\section{ABSTRACT \\ Background}

There are commonly-held views relating to what constitutes appropriate and inappropriate use of finite NHS resources. However, very little is known about how and why such views have an impact on consultation patterns.

Aim

To quantify the prevalence of opinion on whether people use health services unnecessarily within primary care and accident and emergency (A\&E) in order to examine the impact of these views on helpseeking behaviour.

Design of study

A mixed method study utilising cross-sectional questionnaire survey and semi-structured interviews. Setting

A primary care practice in South West England, UK.

Method

Responders to the questionnaire survey were drawn from a random sample of individuals, stratified by sex, selected from one practice in the UK $(n=911)$. The qualitative sample $(n=22)$ were purposefully selected from the same general practice.

\section{Results}

The quantitative data suggest that the majority of people believe individuals utilise either GP or A\&E services inappropriately $(65.6 \%$; $95 \%$ confidence interval $[\mathrm{Cl}]=62.4$ to 68.7$)$. However, strong views relating to this inappropriate healthcare use were not associated with reported seeking of immediate care (odds ratio $[\mathrm{OR}]=0.98,95 \% \mathrm{Cl}=0.66$ to 1.46 for 'lump' vignette). Responders tend to consider other people as time wasters, but not themselves.

Individuals' generally describe clear rationales for help seeking, even for seemingly trivial symptoms and anxiety level was strongly predictive of health-seeking behaviour $(\mathrm{OR}=2.88 ; 95 \% \mathrm{Cl}=1.98$ to 4.19 for lump vignette).

\section{Conclusion}

Perceptions that individuals' use health services inappropriately are unlikely to explain differences in help-seeking behaviours. The findings suggest that people do not take the decision to consult health services lightly and rationalise why their behaviour is not time wasting.

Keywords

mixed-method; patient acceptance of health care; time wasting.

\section{INTRODUCTION}

Among the general public and healthcare providers alike, some individuals are judged to use health services inappropriately. ${ }^{1}$ However, relatively little research has focused primarily on this topic. Much quantitative research has focused on sociodemographic patterns of consultation, with a particular interest in access to services across socioeconomic groups, sex, and age. ${ }^{2}$ A recent review highlights that much of this work has ignored the process of individuals identifying their own candidacy to seek medical care, which is inextricably linked to their readiness to consult. ${ }^{2}$ It has been suggested that readiness to consult is affected by one's identity, ${ }^{2}$ including wanting to be seen as a responsible user. However, there is little research that describes population views of 'appropriate' service use and how this actually has an impact on consultation behaviour.

This study aims to address this gap in the literature by exploring qualitatively and quantitatively the concept of appropriate healthcare use: through describing the prevalence of opinion that people use

J Adamson, PhD, lecturer in epidemiology, Department of Health Sciences, University of York, Heslington, York. Y Ben-Shlomo, PhD, FFPHM, professor; J Donovan, PhD, professor, Department of Social Medicine, University of Bristol, Bristol. N Chaturvedi, PhD, MBBS, professor, Department of Epidemiology and Public Health, Imperial College School of Medicine, London.

Address for correspondence

Joy Adamson, Department of Health Sciences, University of York, Seebohm Rowntree Building, Heslington, York YO10 5DD. E-mail: ja14@york.ac.uk

Submitted: 15 January 2009; Editor's response: 20 March 2009; final acceptance: 18 May 2009.

(c)British Journal of General Practice

This is the full-length article of an abridged version published in print. Cite this article as: Br J Gen Pract 2009; DOI: 10.3399/bjgp09X453530 
services unnecessarily; the impact of views on appropriate healthcare use on reported consultation; and how opinions of what constitutes appropriate healthcare use are operationalised in the justification of help-seeking behaviours of the individual.

\section{METHOD}

A mixed-method approach was used ${ }^{3}-$ defined as the combination of qualitative and quantitative methods within a single study - with the aim of providing a more complete picture of the concept of 'appropriate healthcare use' and its impact on helpseeking behaviour. This was done in two ways: the qualitative research facilitated the quantitative analysis by generating hypotheses for testing; and the qualitative research was used to facilitate the interpretation of findings from the quantitative research. ${ }^{4}$ This process occurred on a cyclical basis.

\section{Quantitative population cross-sectional survey}

A total sample of 1500 individuals, aged between 30 and 75 years, were selected from one primary care practice in the South West of England. The practice was purposefully selected, using census indicators, to ensure that the individuals registered were from a range of socioeconomic backgrounds. Individuals with terminal or serious psychiatric illness were excluded from the sample which was screened by the GP. Questionnaires (pertaining to a range of topics on the subject of help seeking) were posted to participants, and non-responders were sent two reminders followed by a single home visit. Following this process, correct address details were only available for a sub-set of 1287 individuals (based largely on information from post office returns). Further details of the survey are reported elsewhere. ${ }^{5}$

The questionnaire attempted to ascertain the participants' views on whether they believed people used health services unnecessarily. Subjects indicated whether they agreed with the statements 'People use their GP unnecessarily' and 'People use accident and emergency (A\&E) departments unnecessarily' on a five-point scale (strongly agree, agree, all depends/don't know, disagree, and strongly disagree). These questions were taken from the Health and Lifestyles survey. ${ }^{6}$ A dichotomous variable 'People use services unnecessarily' was created by grouping all who stated that they strongly agreed or agreed that people used either the GP or A\&E services unnecessarily. The questionnaire also included two short vignettes describing scenarios that could be related to cardiovascular disease (Box 1) and cancer (Box 2) and where early presentation, diagnosis, and treatment may improve long-term survival. The 'chest pain' scenario (Box 1) had been successfully utilised previously. Vignettes were designed to be gender

\section{How this fits in}

There are commonly-held views relating to what constitutes appropriate and inappropriate use of finite NHS resources. Little is known about how and why such views have an impact on consultation patterns. The study indicated that strong views relating to unnecessary service use were not predictive of reported help seeking. Responders tend to consider other people as time wasters, but not themselves. Perceptions that individuals use health services inappropriately are unlikely to explain differences in consultation behaviours. While patients may consult for seemingly trivial conditions, they rationalise why their behaviour is not unnecessary.

neutral, to encourage participants to identify with the patient, and the clinical problem was designed to be 'grey' so that a range of diagnoses and actions were possible. The 'lump' scenario (Box 2) was in two parts. The second part involved a change in signs and symptoms and was designed to determine how reported attitudes and behaviour would change as the problem progressed. Participants were asked to indicate the actions they would take if they were to experience the symptoms themselves. There were two arms to the response: firstly, whether they would attend the GP or A\&E services and secondly, the urgency with which they would take this action. A dichotomous variable was created to divide responders into those who sought or did not seek 'immediate care'. This was defined as those who stated they would definitely attend casualty or contact the GP immediately in response to the vignette. Responders were also asked to indicate how anxious they were about symptoms (dichotomised into very

\section{Box 1. Vignette 1.}

Chris is 55 years old and has generally good health, but is overweight and doesn't do much exercise. Chris's grandchildren have come to stay for the weekend. Later that evening one of the grandchildren has a headache. Chris starts carrying the child up the stairs to the bedroom. Suddenly, Chris feels a pain in the chest. The pain is so bad that Chris feels a bit sick and has to put the child down. After about 5 minutes, the pain wears off and Chris feels fine. Chris has had the pain once before, following a large meal.

\section{Box 2. Vignette 2.}

$>$ Part I

Pat is 48 years old and is just getting over a cold. While having a bath Pat noticed a small lump in the armpit. Two weeks later the lump was still there and Pat thought it may have got bigger and harder, but wasn't sure. Pat is otherwise well.

$\rightarrow$ Part II

A few weeks later, Pat awoke in the night sweating with a throbbing pain in the armpit with the lump. In the morning Pat could still feel a dull ache in the armpit. 
worried versus reasonably worried/slightly worried/not worried at all); GP consultation in the previous year; family history of chronic illness (number of chronic illnesses); personal history of chronic illness (number of chronic illnesses); and any difficulties accessing GP (including time taken to reach GP and number of access difficulties listed). All of the above measures were based on self-report.

\section{Qualitative interview survey}

Semi-structured interviews with purposively selected informants were used to explore the views of participants relating to illness behaviour. A sampling frame was created to ensure that the sample included both males and females, 'older' and 'younger' age groups, and individuals from a range of socioeconomic backgrounds. The sample was selected from the same general practice that was used for the questionnaire survey. Twenty-two interviews were conducted and the questionnaire survey was used as a 'topic guide'. This involved observing completion of the questionnaire and the responders were asked to 'think aloud' the responses they were making and to describe the reasons underlying the choices they made. This has been described as the 'questerviews' technique. ${ }^{8}$ The process of filling out the questionnaire provoked the telling of many stories by the informants about their experiences of illness and their use of health services. One responder refused permission to record the interview, and in this case detailed notes were taken: all the other interviews were tape recorded and fully transcribed.

\section{Data analysis}

Analysis of both the qualitative and quantitative data was an iterative process, with preliminary results from the qualitative analysis generating hypotheses to be tested using the quantitative data. The qualitative analysis involved reading the interview transcripts and making 'marginal remarks' relating to ideas and thoughts about the text. The transcripts were then reviewed line by line and codes for the text were generated. Initially open codes were generated that were organised into more general themes, with the aim of moving from description to interpretation of the data, using constant comparison techniques..$^{9,10}$ Data were coded within ATLAS/ti. Hypotheses generated from the qualitative analysis were tested using the quantitative data. Multivariable logistic regression (using complete data) analyses were used to present odds ratios $(95 \%$ confidence intervals [Cls] and $P$ values) for the associations between exposure and outcome. Unadjusted and adjusted analyses were carried out and conditioned on the following potential confounding factors: socioeconomic position (measured using a socioeconomic index which was derived from data on car ownership, education, housing tenure, household utilities, and consumer durables); age; sex; previous GP consultation; family history of chronic illness; personal history of chronic illness; and barriers to accessing services. This cyclical pattern was then repeated, with findings from the quantitative analysis being explored further using the qualitative data in an attempt to find explanations for the patterns observed. This in turn led to further hypothesis testing using the quantitative data.

\section{RESULTS}

A total of 911 completed questionnaires were received (response rate $71 \%$ ). Responders were slightly older than non-responders and were more likely to be female. The characteristics of the qualitative sample are presented in Table 1. The sample consisted of 15 females and seven males, with an age range of 35-76 years.

A strong theme to emerge from the qualitative data on healthcare utilisation was the conception of what constituted appropriate use of care. It is this broad theme that provided the basis for further quantitative and qualitative exploration.

There was a prevailing sense of ownership over the NHS which manifests itself in a general notion of

\section{Table 1. Interviewee characteristics.}

\begin{tabular}{|c|c|c|c|}
\hline Responder & Sex & $\begin{array}{l}\text { Age, } \\
\text { years }\end{array}$ & $\begin{array}{l}\text { Standard Occupational } \\
\text { Class of Household }\end{array}$ \\
\hline 1 & $\mathrm{~F}$ & 59 & 1 \\
\hline 2 & M & 51 & 4 \\
\hline 3 & $\mathrm{~F}$ & 50 & 1 \\
\hline 4 & M & 51 & 3.2 \\
\hline 5 & $\mathrm{~F}$ & 63 & 3.2 \\
\hline 6 & M & 74 & 3.1 \\
\hline 7 & $\mathrm{~F}$ & 53 & 3.2 \\
\hline 8 & M & 75 & 2 \\
\hline 9 & $\mathrm{~F}$ & 76 & 5 \\
\hline 10 & M & 60 & 2 \\
\hline 11 & $\mathrm{~F}$ & 41 & 3.1 \\
\hline 12 & $\mathrm{~F}$ & 53 & 3.1 \\
\hline 13 & $\mathrm{~F}$ & 74 & 2 \\
\hline 14 & $\mathrm{~F}$ & 55 & 2 \\
\hline 15 & $\mathrm{~F}$ & 35 & 2 \\
\hline 16 & $\mathrm{~F}$ & 58 & 2 \\
\hline 17 & $\mathrm{~F}$ & 40 & 3.1 \\
\hline 18 & M & 72 & 1 \\
\hline 19 & $\mathrm{~F}$ & 39 & 3.1 \\
\hline 20 & $\mathrm{~F}$ & 38 & 2 \\
\hline 21 & M & 45 & 2 \\
\hline 22 & $\mathrm{~F}$ & 49 & 3.1 \\
\hline
\end{tabular}

aScore: 1 (professional); 2; 3-non-manual; 3-manual; 4; 5 (unskilled). 
being frugal in the demands one places on this shared resource. That, in essence, individuals 'selfration' their use of services, to ensure there are enough resources to go around:

'I mean l've had doctors phone ambulances for me, when my son had appendicitis once but, I always feel a bit sort of reserve, you know, I don't want to sort of bother them. The real issue is there - I don't really want to bother anybody.' (Female, 41)

The quantitative data were examined to determine the prevalence of views pertaining to the appropriateness of healthcare use among a general population and, more importantly, test the hypothesis that these views would have an impact on individual help-seeking behaviour. The quantitative data show that opinions surrounding inappropriate use of either GP or A\&E services were widespread. Over half of the responders (54\%) reported that they either strongly agreed or agreed with the statements relating to inappropriate service use of the GP and A\&E services (Table 2) and the combined variable of 'people use services inappropriately' was even higher, at $65.6 \%$. When it was examined whether this variable was associated with reported help-seeking behaviour, testing the hypothesis that those who agreed that people use services inappropriately would be less likely to report help seeking for standardised symptoms, no evidence of associations was found for any of the symptoms explored (Table 3).

After initial qualitative analysis it appeared that people were self-rationing health services based on firmly-held beliefs regarding what was appropriate and inappropriate use of a scarce resource. However, when it was tested quantitatively whether these views had an impact on reported help-seeking behaviour no evidence of an association was found. Therefore, the qualitative data was revisited to attempt to find an explanation for this finding. Two interlinked themes emerged.

\section{It's other people not me}

An almost universal feature of the interviews was that responders did not discuss instances when they felt they had used services inappropriately; this is despite the prevalent view that other people do this on a frequent basis. For example, two responders had quite different views about the appropriateness of treatment for sore throat:

Table 2. Prevalence of opinions relating to unnecessary use of services.

\begin{tabular}{|c|c|c|c|c|c|}
\hline & $\begin{array}{l}\text { Strongly agree, } n \\
\quad \%(95 \% \mathrm{Cl})\end{array}$ & $\begin{array}{c}\text { Agree, } n \text { All } \\
\%(95 \% \mathrm{Cl})\end{array}$ & $\begin{array}{l}\text { All depends/don't know, } n \\
\%(95 \% \mathrm{Cl})\end{array}$ & $\begin{array}{l}\text { Disagree, } n \\
\%(95 \% \mathrm{Cl})\end{array}$ & $\begin{array}{c}\text { Strongly disagree, } n \\
\%(95 \% \mathrm{Cl})\end{array}$ \\
\hline $\begin{array}{l}\text { People use accident and emergency } \\
\text { departments unnecessarily }\end{array}$ & $\begin{array}{c}155 \\
17.2(14.7 \text { to } 19.8)\end{array}$ & $\begin{array}{c}330 \\
36.5 \text { (33.4 to 39.7) }\end{array}$ & $\begin{array}{c}336 \\
37.2(34.0 \text { to } 40.4)\end{array}$ & $\begin{array}{c}76 \\
8.4(6.7 \text { to } 10.4)\end{array}$ & $\begin{array}{c}7 \\
0.8(0.3 \text { to } 1.6)\end{array}$ \\
\hline People use their GP unnecessarily & $\begin{array}{c}127 \\
14.1(11.9 \text { to } 16.6)\end{array}$ & $\begin{array}{c}362 \\
40.3(37.0 \text { to } 43.6)\end{array}$ & $\begin{array}{c}342 \\
38.0 \text { (34.9 to } 41.3)\end{array}$ & $\begin{array}{c}65 \\
7.2(5.6 \text { to } 9.1)\end{array}$ & $\begin{array}{c}3 \\
0.3(0.1 \text { to } 1.0)\end{array}$ \\
\hline \multicolumn{6}{|l|}{ Derived variable } \\
\hline $\begin{array}{l}\text { People use services inappropriately, } n \\
\text { Yes }^{a} \\
\text { No }\end{array}$ & $(95 \% \mathrm{Cl})$ & $\begin{array}{l}593 ; 65.6 \text { (62.4 to } 68.7 \\
311 ; 34.4 \text { (31.3 to } 37.6\end{array}$ & & & \\
\hline
\end{tabular}

${ }^{a}$ The derived variable 'People use services unnecessarily' was given a value of 'yes' if participants stated they strongly agreed or agreed that people used either the GP or A\&E services unnecessarily, the remaining responses were placed into the negative category.

Table 3. Associations between views on appropriate use of services and reported immediate help seeking for the symptom vignettes from the logistic regression models $(n=788)$.

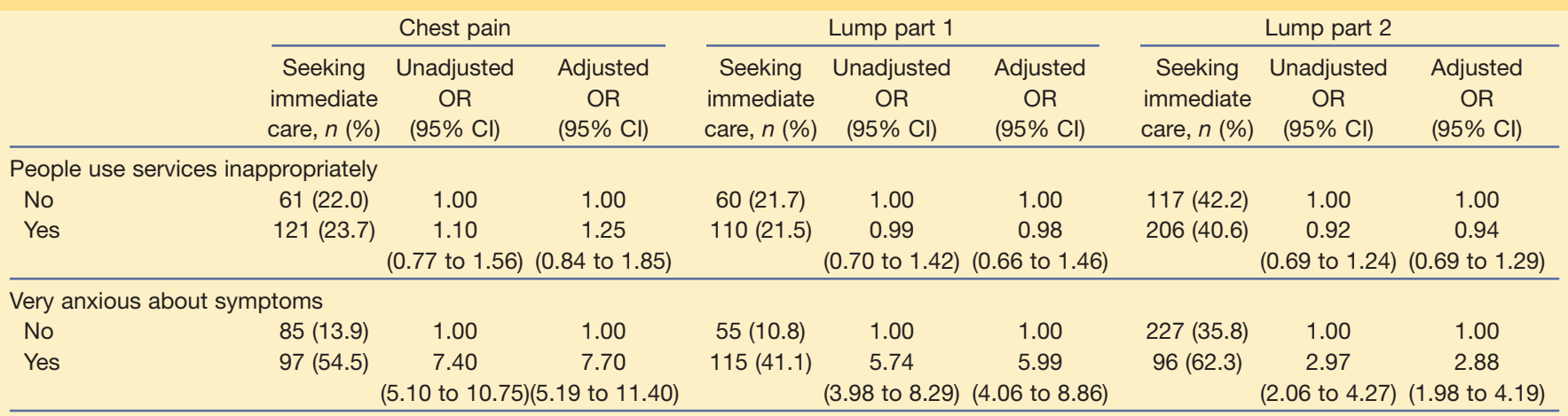

$O R=$ odds ratio 
'I went into A\&E [to work] one night and I had such a sore throat, I just sucked Strepsils ${ }^{\text {tw }}$ and this [patient] was there saying, "oh, l've got such a sore throat", so I said, "have a Strepsil." I would be thinking my god, you know, with a sore throat, only had a sore throat, I wouldn't stand for people like that.' (Female, 38 years)

However, another responder with an unusual family history explained how such attendences might be deemed not unreasonable:

'Last week my husband had a sore throat on the Friday when we finished work and we went to bed and he thought, "oh it's a sore throat it'll probably go away by the time we wake up". Only it didn't, so we started treating it like a sore throat, buying soothers and all the rest. By Saturday it hadn't gone and, of course, Saturday [at the general practice] it's only emergencies, so you still carry on treating it. Come Sunday we had to go up to casualty: it turned out it was tonsillitis ... My brother-in-law, he died last year of TB. After he died obviously the whole family had to go and have tests and everything and we all came out positive. So the children have been having tablets to take, which they're on the second one, they just keep checking us with $x$-rays.' (Female, 41 years)

The first responder (who works as a healthcare provider) was very dismissive of the 'sore throat' patient and by these standards, the second responder would have been branded as a time waster. However, when the decision to seek care for this person is put into context, that they were worried the sore throat was an indication of active tuberculosis, this appears a much more rational decision.

From the interviewee accounts, it appeared that the responders themselves never made flippant or irresponsible decisions relating to service use. However, when making judgements relating to the service use of other individuals, responders tended to assume that other people were not going through the same rational decision-making process as themselves and dismissed the actions of others as time wasting.

\section{Multiple beneficiaries}

On the face of it, comments relating to the collective spirit implied in the use of the NHS appear to reflect a large degree of pure altruism among service users. There is a sense that if the NHS is used fairly then, in the situation of limited resources, another potential service user in greater need would not be deprived of care. While people appear to genuinely hold these views, responders also eluded to the potential for personal gain.

For example, responders recognised the danger in being seen to use services unnecessarily - with the risk of developing a reputation for doing so, which may inhibit personal access to future services. Hence, it is that individual who ultimately will benefit from careful use:

'I feel very comfortable saying to them I really need to see the doctor, but if they didn't know me, if they thought I was a malingerer, they might be a little more resistant.' (Female, 53 years)

Another potential benefit of using services in a responsible way is from the resultant affirmation of a more positive self-identity. For example, individuals' want to be perceived as 'good citizens' and to be seen to act in an appropriate and rational manner. This can be achieved through seeing others as time wasters, while maintaining their perception of their own appropriate use. This is linked to expressions of unnecessary service use as a sign of weakness and that the responders themselves were of a strong constitution:

'You find that people go to the doctor a lot, they're always there. But I mean, I don't bother, I'm not one of these [who] put on my hat and coat because it's raining.' (Male, 60 years)

However, there is a balance to strike, in that, at the same time as not wanting to be regarded as time wasters, the responders also do not want to be judged as obtuse for non-attendance in the presence of a potentially serious symptoms.

It seems there are several reasons for responders wishing to disassociate themselves from the possibility of being a time waster, not least to prevent jeopardising future access to services and having a sense of doing the right thing. This was clearly demonstrated through the ways in which responders rationalised their own help seeking, especially for symptoms that are at risk of appearing trivial to other people, by implicating the importance of dismissing any potential anxiety:

'If it was bothering me, it's not time wasting, for me anyway. It's better to go and have my mind put at rest than have to cause an anxiety to build up.' (Female, 53 years)

Essentially, feeling worried was generally sufficient justification for consultation in response to any symptom. This concept was tested using the quantitative data to examine, for each of the 
symptom vignettes, whether reported anxiety relating to the symptom was associated with immediate care seeking (Table 3). Self-perceived anxiety about the health scenario was a strong predictor of immediate care-seeking behaviour (stronger for the chest pain than lump scenario) and was hardly attenuated after adjustment.

\section{DISCUSSION}

\section{Summary of main findings}

The study sought to describe the prevalence of opinion on appropriate or 'necessary' use of health care and to explore whether such views actually had an impact on reported consultation behaviour. This study's findings suggest that the majority of people subscribed to the view that people use health services unnecessarily. Of those who did not either strongly agree or agree with statements relating to the unnecessary use of either the GP or A\&E services, the majority of those responded in the depends/don't know category - rather than disagreeing with the statement. However, no evidence was found that judgments relating to the appropriateness of service use were predictive of reported consultation across two symptom vignettes.

An almost universal feature of the interviews was that responders did not discuss instances when they felt they had used services inappropriately; this is despite the prevalent view that other people do this on a frequent basis.

\section{Strengths and limitations of the study}

These findings are based on a community sample of patients recruited from a single primary care practice. While this has potential implications for generalisability, a sample was achieved of people who were from a range of different ages, sex, and socioeconomic backgrounds. As highlighted earlier, responders to the quantitative survey were more likely to be older and to be female. However, this is unlikely to have had an impact on the findings from the questionnaire in relation to the associations between attitudes to appropriate use of services and reported help seeking.

The questionnaire study reported here is different from many of the other studies attempting to quantify illness behaviour, as reported consultation behaviour is linked to a predetermined (hypothetical) set of symptoms. It could be argued that reported behaviour in response to artificial symptoms does not necessarily relate to real life behaviour. However, it has been demonstrated that reported tendency to consult is predictive of observed consultation. ${ }^{11,12}$ This approach of using the symptom vignettes has the additional value of standardising symptomatology across all responders.
This study focused on the appropriate use of primary care and A\&E services; this is not to deny other points of contact including NHS Walk-in Centres and NHS Direct. Qualitative evaluations of these services have thrown up issues that are supportive of this study's finding that people seek to avoid being labelled as time wasters, and therefore NHS Direct, for example, can help to avoid any possible sense of this by serving to legitimise helpseeking behaviours. ${ }^{13}$

\section{Comparison with existing literature}

One of the mechanisms by which increasing demand on health services has been managed has been to 'invoke a discourse of citizenship, to encourage consumers not to exercise their rights by being greedy in their demands of health products'. ${ }^{1}$ A number of qualitative papers have highlighted the extent to which individuals are highly sensitive to the demands on the NHS, are anxious not to be seen as time wasters, nor using resources in place of those more deserving. ${ }^{1,13,14}$

The 'clinical iceberg', ${ }^{15}$ referring to the phenomenon that most symptoms are not reported to health services, is well documented. The decision not to seek care is based on a complex interplay of factors. ${ }^{2,16}$ As demonstrated in this study and elsewhere in the literature, while individuals judge other people as time wasters they often do not apply this to themselves, justifying their own use of services in a rational manner, even for apparently 'trivial' symptoms. ${ }^{1}$ In addition, when examining the differences between consulters and non-consulters for cough, it was observed that the consulting patients did not assess cough as a trivial illness. ${ }^{17}$

More generally a distinction has been made between how the 'actor' and 'observer' perceive the causes of behaviour:

'Actors tend to attribute the causes of their behaviour to stimuli inherent in the situation, while observers tend to attribute behaviour to stable dispositions of the actor. ${ }^{, 18}$

According to this position, when assessing their own behaviour, the person seeking care will see this decision in light of all of the factors they have taken into consideration. This information is largely unavailable to the person observing this action, who will tend to over-attribute this behaviour to the traits of the individual. Because of this, the actor will often view their own behaviour as being more appropriate to given situations than the behaviour of others.

Some of the themes uncovered in the study echo issues identified previously, albeit in other contexts. For example, it was found that 'self-rationing' 
behaviour could also have self-profiting outcomes, ultimately making future encounters more legitimate. It had previously been noted that mothers ration their own use of health care to add legitimacy to the use of primary care for their children. ${ }^{16}$ Such notions have been examined in the economics of individual motivations, whereby some authors have discussed ways in which individuals seek selfish gains through 'other regarding behaviour', altruism being one example of this. ${ }^{19}$

Other authors have identified those who present themselves as stoical and strong as opposed to the weakness of persistent help-seeking patients, referring to this as a 'moral' dimension to the decision whether or not to consult. ${ }^{20}$ The finding is reminiscent of 'warm-glow' altruism, which captures the phenomenon of the personal satisfaction to be gained by acting to benefit others, in this case, by not using finite service provision inappropriately. ${ }^{21}$

Despite a relatively widespread literature in support of patients operating a collectivist model of health care in which they 'negotiate an identity of responsible health citizen', ${ }^{1}$ it is interesting that there was no strong evidence of an association between believing that people use services unnecessarily and reported consultation in response to two symptom vignettes. It is possible that this finding is an artefact of the data collection mechanisms, some of which have been discussed above, however, this resonates with Mechanic's distinction between 'cross-sectional' and 'processual studies', ${ }^{22}$ which essentially relate to the quantitative and qualitative components respectively:

'In theory people with identical symptoms might behave differently depending on what is going on in their lives and on situational factors, and this cannot be captured through cross-sectional study. ${ }^{22}$

Mechanic argues that determinants of consultation cannot simply be abstracted through general descriptors of the person involved or their environment; supporting this with evidence relating to the small amount of variance explained in large multivariable models of healthcare consultation, even when a large number of predictor variables are used. This may explain the lack of associations noted between the strong qualitative theme of unnecessary health service use and reported help seeking in this analysis.

The study provides an example of inter-method mixing, whereby the combining of qualitative and quantitative findings takes place at the analysis/interpretation phase. ${ }^{23}$ Examples of how to perform the 'third effort', ${ }^{24}$ of connecting what can be learned from each component, have been relatively sparse. In this study the qualitative and quantitative components were conducted in parallel, no dominance was given to either method, and the integrity of each method was kept intact. The qualitative study was conducted in the normal way but with elements of the structured questionnaire as part of the topic guide. Overlapping the topics covered in both the qualitative and quantitative components in this way forges a path to integration at the interpretation phase. ${ }^{3}$

\section{Implications for future research and clinical practice}

Perceptions that individuals use health services inappropriately are prevalent, yet are unlikely to have an impact on help-seeking behaviours in simple ways. An individual's decision to take action (or inaction), in response to experiencing symptoms, is based on a complex interplay of factors. However, it appears that while people hold strong views about the appropriate use of care, these are largely based on the assumed actions of other people. The findings suggest that people do not take the decision to consult health services lightly and wish to avoid potentially time-wasting behaviours. Therefore, patients who present with seemingly trivial symptoms have exceeded their personal thresholds for the trade off between not wishing to use services inappropriately versus the anxiety caused by the experience of symptoms.

\section{Funding body}

The research was funded by the UK South \& West NHS Research and Development Directorate [C/MV/10/04.97/Donovan]

\section{Ethic approval}

The study had full approval from the Local Research Ethics Committee (LREC Project 45/97)

\section{Competing interests}

The authors have stated that there are none

\section{Acknowledgements}

The authors would like to express our gratitude to the responders who took the time to complete the postal questionnaire and the qualitative interviews.

\section{Discuss this article}

Contribute and read comments about this article on the Discussion Forum: http://www.rcgp.org.uk/bjgp-discuss

\section{REFERENCES}

1. Goode J, Greatbatch D, O'Cathain A, et al. Risk and the responsible health consumer: the problematics of entitlement among callers to NHS Direct. Critical Social Policy 2004; 24(2): 210-232.

2. Dixon-Woods M, Kirk D, Agarwal S, et al. Vulnerable groups and access to health care: a critical interpretive review. Report for the National Co-ordinating Centre for NHS Service Delivery and Organisation R\&D (NCCSDO). London: Department of Health, 2005.

3. Adamson J. Combined qualitative and quantitative designs. In: Bowling A, Ebrahim S, (eds). Handbook of health research methods. Maidenhead: Open University Press, 2005: 230-245.

4. O'Cathain A, Thomas K. Combining qualitative and quantitative methods. In: Pope C, Mays N, (eds). Qualitative research in health 
care. 3rd edn. Oxford: Blackwell Publishing, 2006: 102-111.

5. Adamson J, Ben-Shlomo Y, Chaturvedi N, Donovan J. Ethnicity, socio-economic position and gender - do they affect reported health-care seeking behaviour? Soc Sci Med 2003; 57(5): 895-904.

6. Blaxter M. Health and lifestyles. 1st edn. London: Tavistock and Routledge, 1990.

7. Chaturvedi N, Rai H, Ben-Shlomo Y. Lay diagnosis and health-careseeking behaviour for chest pain in South Asians and Europeans. Lancet 1997; 350(9091): 1578-1583.

8. Adamson J, Gooberman-Hill R, Woolhead G, Donovan J. 'Questerviews': using questionnaires in qualitative interviews as a method of integrating qualitative and quantitative health services research. J Health Serv Res Policy 2004; 9(3): 139-145.

9. Strauss A, Corbin J. Basics of qualitative research. Newbury Park, CA: SAGE Publications, 1990.

10. Miles MB, Huberman AM. Qualitative data analysis. London: SAGE Publications, 1994.

11. Van der Meer JBW, Mackenbach JP. Low education high GP consultation rates: the effect of psychosocial factors. J Psychosom Res 1998; 44(5): 587-597.

12. Reijneveld S, Stronks K. The validity of self-report use of health care across socioeconomic strata: a comparison of survey and registration data. Int J Epidemiol 2001; 30(6): 1407-1414.

13. O'Cathain A, Goode J, Luff D, et al. Does NHS Direct empower patients? Soc Sci Med 2005; 61(8): 1761-1771.

14. Jackson CJ, Dixon-Woods M, Hsu R, Kurinczuk JJ. A qualitative study of choosing and using an NHS Walk-in Centre. Fam Pract 2005; 22(3): 269-274.
15. Last J. The iceberg: 'completing the clinical picture' in general practice. Lancet 1963; ii: $28-31$.

16. Rogers A, Hassell K, Nicolaas G. Demanding patients? Analysing the use of primary care. Buckingham: Open University Press, 1999.

17. Cornford C. Why patients consult when they cough: a comparison of consulting and non-consulting patients. Br J Gen Pract 1998; 48(436): 1751-1754.

18. Jones EE, Nisbett RE. The actor and the observer: divergent perceptions of the causes of behaviour. In: Jones EE, Kanouse DE, Kelley HH, et al (eds). Attribution: perceiving the causes of behaviour. Morristown, NJ: General Learning Press, 1972: 79-94.

19. Schram A. Sorting out the seeking: the economics of individual motivations. Public Choice 2000; 103(3-4): 231-258.

20. Calnan M, Wainwright D, O’Neill C, et al. Illness action rediscovered: a case study of upper limb pain. Sociol Health Illn 2007; 29(3): 321-346.

21. Andreoni J. Impure altruism and donations to public goods: a theory of warm-glow giving. Econ J 1990; 100(401): 464-477.

22. Mechanic D. Correlates of physician utilization: why do major multivariate studies of physician utilization find trivial pyschosocial and organizational effects? J Health Soc Behav 1979; 20(4): 387-396.

23. Johnson B, Turner LA. Data collection strategies in mixed methods research. In: Tashakkori A, Teddlie C, (eds). Handbook of mixed methods in social and behavioral research. 1st edn. Thousand Oaks, CA: Sage Publications, 2003

24. Morgan D. Practical strategies for combining qualitative and quantitative methods: applications to health research. Qual Health Res 1998; 8(3): 362-376. 